\title{
Negative Soil Respiration Fluxes in Unneglectable Arid Regions
}

\author{
WenFeng Wang ${ }^{1}, \mathrm{Xi}$ Chen ${ }^{1 *}$, Zhi Pu², XiuLiang Yuan ${ }^{1}$, JinLong Ma ${ }^{1}$ \\ ${ }^{1}$ State Key Laboratory of Desert and Oasis Ecology, Xinjiang Institute of Ecology and Geography, \\ Chinese Academy of Sciences, Urumqi, 830011, China \\ ${ }^{2}$ College of Computer and Information Engineering, Xinjiang Agricultural University, \\ Urumqi 830052, China
}

Received: 22 January 2014

Accepted: 28 March 2014

\begin{abstract}
This study examines the hypothesis that soil respiration fluxes are always positive, neglecting negative fluxes in arid regions that characterize more than $30 \%$ of Earth's total land area. To cut down uncertainty, we focus on non-vegetated areas at a typical, large arid region (Central Asia). Soil respiration fluxes were reconciled as a direct sum of influxes $\left(\mathrm{CO}_{2}\right.$ fluxes entering soils) and effluxes $\left(\mathrm{CO}_{2}\right.$ fluxes released from soils). It was indicated that the annual average of effluxes was only 8\% higher than that of influxes in 1979-2011. At typically alkaline sites (soil $\mathrm{pH}>9.5$ ), extreme local annual average of soil respiration fluxes are negative. Therefore, negative soil respiration fluxes in arid regions are unneglectable. Although the soil respiration flux is useful as a measure of $\mathrm{CO}_{2}$ effluxes from the soils and $\mathrm{CO}_{2}$ influxes to the soils, its value as a measure of ecosystem processes is very much limited.
\end{abstract}

Keywords: soil respiration flux, influxes and effluxes, climate changes

\section{Introduction}

Soils provide the second largest $\mathrm{CO}_{2}$ fluxes (effluxes) from terrestrial ecosystems to the atmosphere $[1,2]$ and have significant implications to the global carbon balance [3-5]. Conventionally, these fluxes are comprised of two biological components controlled by distinct processes, namely the autotrophic respiration of plant root and the decomposition of soil organic carbon (SOC) by fauna and microbes (heterotrophic respiration), during which soil $\mathrm{CO}_{2}$ is released [6-8]. Not surprisingly, soil respiration fluxes were always thought to be positive and significantly contributed to the increasing atmospheric $\mathrm{CO}_{2}[9,10]$. However, recent studies in some arid and semiarid ecosystems demonstrated that soil respiration flux in special arid regions can be temporally negative, in which $\mathrm{CO}_{2}$ flux

*e-mail: chenxi@ms.xjb.ac.cn entered rather than was released from the ground [11, 12]. The negative fluxes cannot be attributed to the biological processes. To rationalize these negative fluxes, some nonbiological processes, such as $\mathrm{pH}$-mediated $\mathrm{CO}_{2}$ dissolution and diffusion in soils and the surface adhesion of $\mathrm{CO}_{2}$ onto the soil minerals, were suggested, contributing the third dominant soil respiration flux in arid regions [13-16]. Despite of all these studies, however, the significance of soil $\mathrm{CO}_{2}$ influx in the total soil respiration flux remains undetermined and the magnitude of negative soil respiration flux in arid regions is still a matter of controversy [1719]. Arid regions characterize more than $30 \%$ of the Earth's total land surface and are still increasing due to the global trend toward increasing desertification $[16,20]$. To cut down uncertainties in the global/regional carbon balance and in the prediction of future feedbacks in the coupled carbon-climate system, it is crucial to determine whether negative soil respiration flux in arid regions are worthy of being 
taken into account $[14,19]$. Hence we reconciled the soil respiration fluxes as a direct sum of $\mathrm{CO}_{2}$ influxes and effluxes and significance of negative soil respiration flux in arid regions was evaluated according to a comparison of annual intensities of influxes and effluxes at a typical, large arid region (Central Asia) in the past three decades (19792011).

\section{Materials and Methods}

Analyses in this study were based on the output data of an incorporated model for soil respiration flux $\left(\mathrm{F}_{\mathrm{c}}\right)$ in arid land [21]. The input data of the incorporated model (including the surface air temperature, $\mathrm{T}_{\mathrm{a}}$ ), soil volumetric water content $\left(\theta_{\mathrm{s}}\right)$ at $5 \mathrm{~cm}$ depth were collected from the Xinjiang and Central Asia Scientific Data Sharing Platform, where we got access of the data of $\mathrm{T}_{\mathrm{a}}, \theta_{\mathrm{s}}$, and annual precipitation (AP) for Central Asia (only considering the area with elevation $<1500 \mathrm{~m}$ ) in 1979-2011.

Temporal and spatial variations of $\mathrm{pH}$ are very important for the estimation of soil $\mathrm{CO}_{2}$ flux. But there are no reliable and prepared data of temporal and spatial variations in $\mathrm{pH}$ at Central Asia in 1979-2011. To reduce uncertainty, a constant $\mathrm{pH}$ value (8.5) was applied, hypothetically representing the mean $\mathrm{pH}$ value at the large region in the past three decades.

A temperature-dependent $\mathrm{Q}_{10}$ model (the derivative of the exponential chemical reaction-temperature equation originally developed by Van't Hoff) has been widely performed around the world to estimate the temperature sensitivity of soil respiration fluxes (i.e., $F_{c}$ ) and predict the future feedbacks of $F_{c}$ to climate change [22-24]. However, for arid regions where negative soil respiration fluxes frequently occur [13], the $\mathrm{Q}_{10}$ model must be refomulated as an incorporative model $[18,21]$ :

$$
\left\{\begin{array}{c}
F_{\mathrm{c}}=F_{a}+F_{x} \\
F_{a}=R_{10} Q_{10}{ }^{(T-10) / 10} \\
F_{x}=r_{7} q_{7}^{p H-7}+\lambda T+\mu \theta_{S}+e
\end{array}\right.
$$

...where the database of $F_{c}$ was divided into two subdatasets of soil organic respiration $\left(\mathrm{F}_{\mathrm{a}}\right)$ and soil inorganic respiration $\left(\mathrm{F}_{\mathrm{x}}\right) ; \lambda=0.0059, \mu=0.0003, \mathrm{r}_{7}=3.0191, \mathrm{q}_{7}=0.7562$, $\mathrm{e}=-2.5081, \mathrm{R}_{10}=0.3625$, and $\mathrm{Q}_{10}=1.5$.

These parameters are hypothetically applicable worldwide in this study, and so the model has global implications. To calculate $\mathrm{F}_{\mathrm{e}}$ and $\mathrm{F}_{\mathrm{i}}$, similar to Chen et al. [18], two half components of $F_{x}, F_{x+}$, and $F_{x-}$, termed as efflux and influx in $\mathrm{F}_{\mathrm{x}}$, respectively, were defined as:

$$
F_{x+}=\left(F_{x}+\left|F_{x}\right|\right) / 2 \quad F_{x-}=\left(F_{x}-\left|F_{x}\right|\right) / 2
$$

... and hence $\mathrm{F}_{\mathrm{c}}$ was reconciled as a direct sum of soil $\mathrm{CO}_{2}$ effluxes $\left(\mathrm{F}_{\mathrm{e}}\right)$ and influxes $\left(\mathrm{F}_{\mathrm{i}}\right)$, which were respectively formulated as:

$$
F_{e}=F_{a}+F_{x+} \quad F_{i}=F_{x-}
$$

To determine the contributions of $F_{e}$ and $F_{i}$ in $F_{c}$, an index E/I was naturally defined as:

$$
E / I=F_{e} /\left|F_{i}\right|=-F_{e} / F_{i}
$$

This calculated E/I at the given $\mathrm{pH}$ (8.5). In order to further consider the variations of (the temporal and spatial average of $\mathrm{F}_{\mathrm{c}}\left(\mu \mathrm{mol} \cdot \mathrm{m}^{-2} \cdot \mathrm{s}^{-1}\right)$ with $\mathrm{pH}$, the results were evaluated as well to investigate the dynamics of soil $\mathrm{CO}_{2}$ fluxes at the local extremes of $\mathrm{pH}(8.1-8.5$; see $[18,21])$. This generated the contours of the annual soil respiration at the Central Asia annual) in the past three decades (coordinated to the year and soil $\mathrm{pH}$ ).

\section{Results and Discussions}

Annual soil $\mathrm{CO}_{2}$ effluxes were only $8 \%$ higher than soil $\mathrm{CO}_{2}$ influxes at non-vegetated soil sites at Central Asia in the last three decades (referring to the trend of E/I; Fig.1). Negative soil respiration fluxes in the typical, large arid regions are unneglectable and hence must be taken into account in the budget of $F_{c}$ in arid and semiarid ecosystems. This is essentially significant to cut down uncertainties in the global $\mathrm{C}$ budget accounting and in predictions of future feedback in the coupled carbon-climate systems. From 1979 to 2011 there is a significant decrease in the annual total precipitation and a corresponding decrease in $\theta_{\mathrm{s}}$. But there are no significant fluctuations in $\mathrm{T}_{\mathrm{a}}$ and $\mathrm{E} / \mathrm{I}$. The significance of negative $\mathrm{CO}_{2}$ fluxes (E/I) was sensitive to temperature changes since $\mathrm{T}_{\mathrm{a}}$ and $\mathrm{E} / \mathrm{I}$ at Central Asia exhibited a similar pattern in the past three decades.

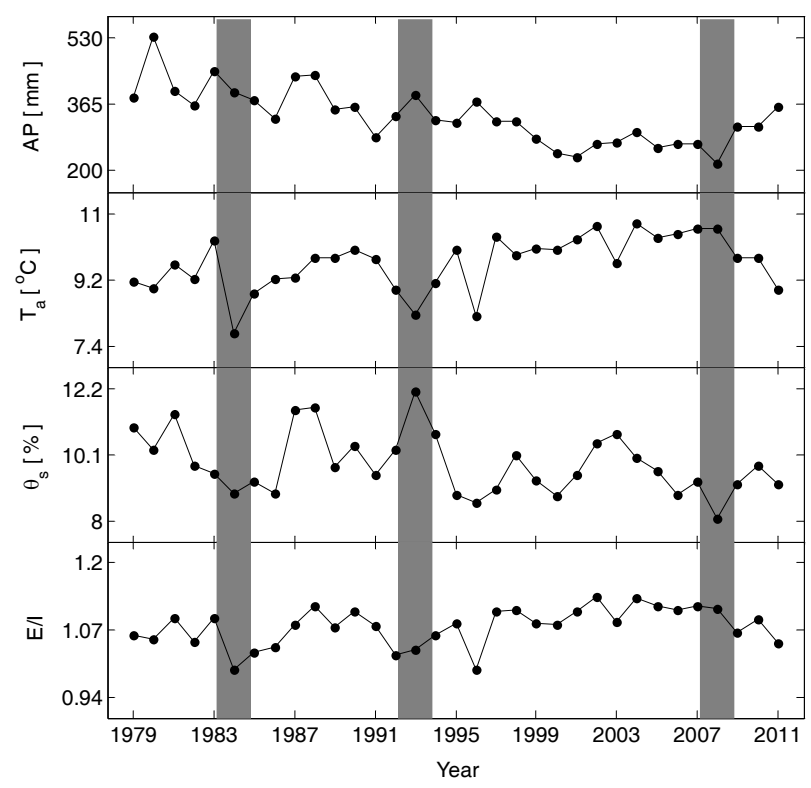

Fig. 1. Trends of climate changes in Central Asia in 1979-2011 ( $\mathrm{a}$ - annual precipitation, $\mathrm{b}$ - surface air temperature, $\mathrm{c}-$ soil volumetric water content at $5 \mathrm{~cm}$ depth) and significance of negative $\mathrm{CO}_{2}$ fluxes ( $\mathrm{d}$ - evaluated by the index E/I) in Central Asia 1979-2011. 


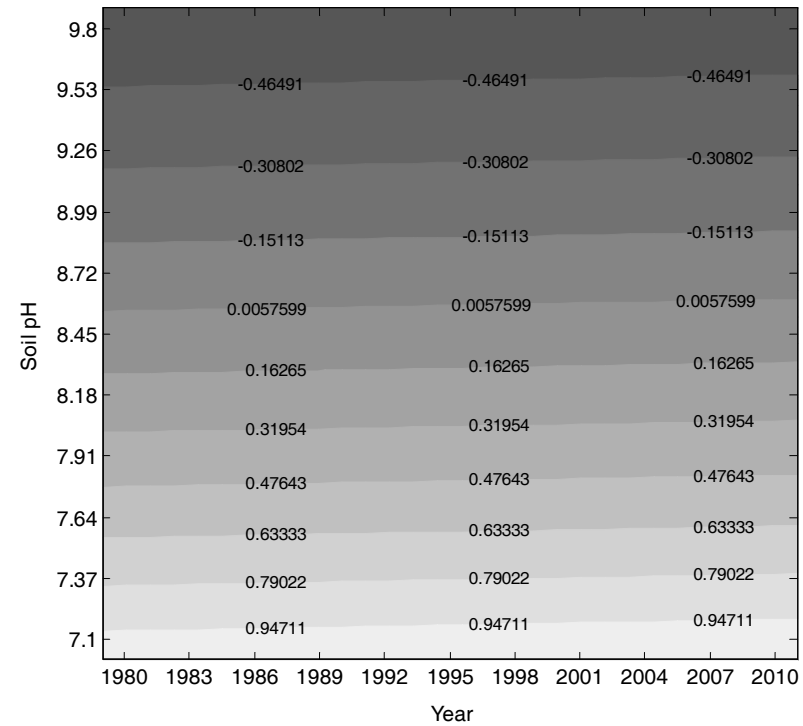

Fig. 2. Contours of annual soil respiration $\left(\mu \mathrm{mol} \cdot \mathrm{m}^{-2} \cdot \mathrm{s}^{-1}\right)$ in Central Asia in the past three decades (coordinated to the year and soil $\mathrm{pH}$ ).

Contours of annual soil respiration $\left(\mu \mathrm{mol} \cdot \mathrm{m}^{-2} \cdot \mathrm{s}^{-1}\right)$ in Central Asia in the past three decades (coordinated to the year and soil $\mathrm{pH}$ ) implied that the significance of negative soil respiration fluxes are decreasing in the past decades (Fig. 2). Referring to Fig. 1, such a decrease is largely driven by regional warming. At soil sites with $\mathrm{pH}<8.1$, the average annual soil respiration fluxes are positive. But at soil sites with $\mathrm{pH}>9.5$, the annual soil respiration fluxes are negative, implying that the extreme local soil respiration fluxes are largely negative.

There is strong evidence suggesting that negative soil respiration fluxes exert potential influences on the dynamics of soil respiration fluxes in arid regions. Note that arid regions characterize more than $30 \%$ of the Earth's land surface, and are still increasing due to the regional/global trend towards increasing desertification, the negative soil respiration flux in arid regions are worthy of being taken into account in evaluating the regional and global carbon balance [14].

Significance of negative soil respiration flux also highlighted the difference between "the real soil respiration" (dominantly biological) and "the apparent soil respiration" (dominantly non-biological at local extremes). The interpretation of soil respiration fluxes as biological processes (including autotrophic and heterotrophic respiration) is only true for real soil respiration, but it was not true for the measured $F_{c}$, which could only represent "apparent soil respiration" [18]. Because of the complicated porous structure, a part of the $\mathrm{CO}_{2}$ effluxes from the real soil respiration are delayed and subsequently released in a physical diffusion [21]. Especially after precipitation, the infiltration of water reduces the stored space for $\mathrm{CO}_{2}$ in the soil and always aggravates the $\mathrm{CO}_{2}$ release in $\mathrm{F}_{\mathrm{c}}$ (the so-called Birch effect), which can be largely attributed to non-biological processes [13]. Negative soil respiration fluxes are important for understanding the carbon cycle in arid and semiarid ecosys- tems [16]. The whole story of the little-known non-biological $\mathrm{CO}_{2}$ absorption by soils and its overall importance on the regional and global carbon balance are worthy of further exploration [15].

\section{Conclusion}

Although $\mathrm{F}_{\mathrm{c}}$ is useful as a measure of $\mathrm{CO}_{2}$ fluxes from the soils, its value as a measure of ecosystem processes is very much limited. Since negative $\mathrm{CO}_{2}$ fluxes observed with both chambers and the open- or close-path eddy systems were still included in the nocturnal data of ecosystem respiration, it should not be excluded from the data of soil respiration flux in arid and semiarid ecosystems. The $Q_{10}$ model applied to these ecosystems must be replaced with a developed form to adopt negative fluxes.

\section{Acknowledgements}

This research was financially supported by the International S\&T Cooperation Program of China (2010DFA92720-13). The authors thank the anonymous referees for their careful reading, detailed comments, and many constructive suggestions which greatly improved our presentation.

\section{References}

1. COX P. M., BETTS R. A., JONES C. D., SPALL S. A., TOTTERDELL I. J. Acceleration of global warming due to carbon-cycle feedbacks in a coupled climate model. Nature. 408, 184, 2000.

2. SCHLESINGER W. H, ANDREWS J. A. Soil respiration and the global carbon cycle. Biogeochemistry. 48, 7, 2000.

3. BOND-LAMBERTY B., THOMSON A. A global database of soil respiration data. Biogeosciences. 7, 1915, 2010.

4. GIARDINA C., RYAN M. Evidence that decomposition rates of organic carbon in mineral soil do not vary with temperature. Nature. 404, 858, 2000.

5. KIRSCHBAUM M. U. F. The temperature dependence of soil organic matter decomposition and the effect of global warming on soil organic C storage. Soil Biol. Biochemi. 27, 753, 1995.

6. BAGGS E. M. Partitioning the components of soil respiration: a research challenge. Plant Soil. 284, (1-2), 1, 2006.

7. BALDOCCHI D. D. Assessing the eddy covariance technique for evaluating carbon dioxide exchange rates of ecosystems: past, present and future. Global Change Biol. 9, (4), 479, 2003.

8. VALENTINI R., MATTEUCCI G., DOLMAN A. J. SCHULZE E. D., REBMANN C., MOORS E. J., GRANIER A., GROSS P., JENSEN N. O., PILEGAARD K., LINDROTH A., GRELLE A., BERNHOFER C., GRÜNWALD, T., AUBINET M., CEULEMANS R., KOWALSKI A. S., VESALA T., RANNIK Ü., BERBIGIER P., LOUSTAU D., GUĐMUNDSSON J., THORGEIRSSON H., IBROM A., MORGENSTERN K., CLEMENT R., MONCRIEFF J., MONTAGNANI L., MINERBI S., JARVIS P. G. Respiration as the main determinant of carbon balance in European forests. Nature. 404, (6780), 861, 2000. 
9. IPCC. Climate Change 2007: The Physical Sciences Basis: Contribution of Working Group I to the Fourth Assessment Report of the Intergovernmental Panel on Climate Change. Cambridge University Press, Cambridge, 2007.

10. WANG X. H., PIAO S. L., CIAIS P., JANSSENSC I. A., REICHSTEIND M., PENG S. S., WANG T. Are ecological gradients in seasonal $\mathrm{Q}_{10}$ of soil respiration explained by climate or by vegetation seasonality? Soil Biol. Biochemi. 42, 1728, 2010.

11. LAI L. M., ZHAO X., JIANG L., WANG Y. J., LUO. L. G., ZHENG Y. R., CHEN X., RIMMINGTON G. M. Soil respiration in different agricultural and natural ecosystems in an arid region. Plos One. 7, (10), e48011, 2012.

12. ZHANG L. H., CHEN Y. N., ZHAO R. F., LI W. H. Significance of temperature and soil water content on soil respiration in three desert ecosystems in Northwest China. J. Arid Environ. 74, 1200, 2010.

13. MA J., WANG Z. Y., STEVENSON B. A., ZHENG X. J., LI Y. An inorganic $\mathrm{CO}_{2}$ diffusion and dissolution process explains negative $\mathrm{CO}_{2}$ fluxes in saline/alkaline soils. Scientific Reports. doi:10.1038/srep02025, 2013.

14. STONE R. Have desert researchers discovered a hidden loop in the carbon cycle? Science. 320, (5882), 1409 , 2008.

15. XIE J. X., LI Y., ZHAI C. X., LI C. H., LAN Z. D. $\mathrm{CO}_{2}$ absorption by alkaline soils and its implication to the global carbon cycle. Environ. Geol. 56, (5), 953, 2009.

16. YATES E. L., DETWEILER A. M., IRACI L. T., BEBOUT B. M., MCKAY C. P., SCHIRO K., SHEFFNER E. J., KEL-
LEY C. A., TADIC J. M., LOEWENSTEIN M. Assessing the role of alkaline soils on the carbon cycle at a playa site. Environ. Earth. Sci. 70, (3), 1047, 2013.

17. CHEN X., WANG W. F., LUO G. P., LI L. H., LI Y. Time lag between carbon dioxide influx to and efflux from bare saline-alkali soil detected by the explicit partitioning and reconciling of soil $\mathrm{CO}_{2}$ flux. Stoch. Env. Res. Risk A. 27, (3), 1, 2013.

18. CHEN X., WANG W. F., LUO G. P., YE H. Can soil respiration estimate neglect the contribution of abiotic exchange? J. Arid Land. 6, (2), 1, 2014

19. SCHLESINGER W. H., BELNAP J., MARION G. On carbon sequestration in desert ecosystems. Global Change Biol. 15, (6), 1488, 2009.

20. EMMERICH W. E. Carbon dioxide fluxes in a semiarid environment with high carbonate soils. Agr. Forest Meteorol. 116, (1), 91, 2003.

21. WANG W. F., CHEN X., LUO G. P., LI L. H. Modeling the contribution of abiotic exchange to $\mathrm{CO}_{2}$ flux in alkaline soils of arid areas. J. Arid Land. 6, (1), 27, 2014.

22. YUSTE J. C., BALDOCCHI D. D., GERSHENSON A., GOLDSTEIN A., MISSON L., WONG. S. Microbial soil respiration and its dependency on carbon inputs, soil temperature and moisture. Glob Chang Biol. 13, 2018, 2007.

23. VAN'T HOFF J. H. Lectures on theoretical and physical chemistry. Part I: Chemical Dyanmics. Trans. Lehfeldt R A. Edward Arnold, London, pp. 224-229, 1898.

24. LLOYD J., TAYLOR J. A. On the temperature dependence of soil respiration. Funct. Ecol. 8, 315, 1994. 